\title{
Populismo y derechos ciudadanos: anotaciones sobre un vínculo errante
}

\section{Populism and civil rights:}

\author{
notes on a wandering link
}

\author{
Virginia Morales* y Mercedes Barros**
}

\begin{abstract}
RESUMEN: En el presente artículo se aborda la relación entre populismo y derechos ciudadanos desde una perspectiva histórica y política, atendiendo a ciertos aspectos atribuibles al populismo en tanto fenómeno políitco específico y enfocando el análisis en una experiencia histórica determinada de los así llamados populismos clásicos. Puesto que de manera reiterada se ha señalado que los regímenes populistas suponen una convivencia conflictiva en el ejercicio efectivo de los derechos y libertades individuales, el objetivo del artículo se encamina a contribuir al esclarecimiento de esta tensión. En particular, se centra en la experiencia políicica del primer peronismo, dirigiendo la mirada sobre las implicaciones de este vínculo en la base de la sociedad. Para tal propósito, se recuperan ciertas matrices textuales heterodoxas, a través de las cuales se busca dilucidar la experiencia subjetiva que se forió en torno al ejercicio de los derechos ciudadanos con el telón de fondo del discurso peronista.
\end{abstract}

Palabras Clave: Populismo, Derechos ciudadanos, Peronismo.

ABSTRACT: This paper addresses the relationship between populism and civil rights from a political and historical perspective, paying attention to certain theoretical approaches that can be attributed to populism understood as a specific political phenomenon and focusing analysis on a certain historical experience of so called classical populisms. As time and time again it has been suggested that populism imply a conflictive coexistence between the effective exercise of individual rights and its freedoms. The aim of this paper is to feed the clarification of this tension. It focuses on the political experience of first peronismo. The paper aims to contribute to the clarification of the tension that characterizes this link, particularly focusing on its implications at the base of society. For this purpose, we recover certain heterodox textual matrices, in which we hope to elucidate the subjective experience that was forged around the exercise of civil rights against the backdrop of Peronist discourse.

Key WordS: Populism, Civil Rights, Peronism.

Recibido: 9 de abril de 2018

Aceptado: 3 de julio de 2018

CONICET/Universidad Nacional de Villa María (mvirginiamorales22@gmail.com).

CONICET/Universidad Nacional de Río Negro (mercedesbarros@gmail.com). 
Somos tan humildes como el más humilde de los obreros y deseamos estar amparados por los mismos derechos que ellos.

Carta a Juan D. Perón.

[Lo seguimos] por la lucha que nos brindó, para elevarnos un poco, para bacernos tomar conciencia de nuestros derechos humanos, de los derechos que se nos deben. Julio Rocha, seguidor de Víctor Raúl Haya de la Torre.

\section{INTRODUCCIÓN}

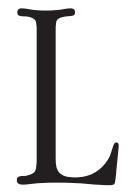

a emergencia de experiencias políticas de tinte populista en varios países latinoamericanos durante los primeros años del siglo XXI, vigorizó un debate que parecía saldado frente al aparente triunfo de la democracia liberal en el continente. Por cierto, los gobiernos de Nestor Kirchner y Cristina Fernández de Kirchner en Argentina (20032015); de Lula da Silva en Brasil (2003-2011); de Evo Morales en Bolivia (2006 a la fecha); de Rafael Correa en Ecuador (2007-2017), y de Hugo Chávez en Venezuela (1999-2013), actualizaron la centralidad del populismo dentro del campo de las ciencias sociales, propiciando múltiples puntos de vista en torno a la naturaleza de este fenómeno político, a su especificidad teórica, como así también respecto de sus consecuencias en tanto práctica política concreta. A propósito de este debate, junto con el renovado interés en los populismos "clásicos", se reanudaron viejas discusiones sobre los desencuentros entre un ordenamiento político de tipo populista y las formas institucionales de los regímenes democráticos (Abts y Rummens 2007; Panizza 2008). Como se ha señalado, las configuraciones populistas irrumpen de manera incómoda en la articulación entre democracia y liberalismo, generando el espectro de una tiranía con apoyo popular y nuevas relaciones de poder, que contrastan con las formas liberal republicanas de representación e identificación política (Panizza 2009; Lichtmajer 2002). Así pues, ante la suposición de fuertes liderazgos populares, sobrecargados de autoridad, la estabilidad del sistema democrático 
se ve amenazada por un poder político discrecional, paternalista y vertical que, en nombre del pueblo soberano, forcejea los límites de lo legítimo y de lo legalmente posible. Precisamente, sobre esa tensión se inscriben varias evocaciones que sostienen la incompatibilidad entre los proyectos políticos de tipo populistas y el respeto y ejercicio efectivo de los derechos civiles y políticos (Alegre 2016; Olivares 2015). Cierto es que, a la luz de coyunturas políticas que frecuentemente propician posturas contrapuestas, el debate ha quedado atascado en la polémica entre los detractores y los defensores del populismo respecto de las manifestaciones históricas específicas; resultando esta tensión (que se sospecha constitutiva) también ocluida en dicha disputa. Por lo tanto, el abordaje del vínculo entre el populismo y el ámbito de los derechos ciudadanos, frecuentemente se ajusta y mueve de forma pendular entre la ponderación del populismo como promotor de una ciudadanía en expansión, y su denostación en tanto artífice del atropello de las libertades y derechos individuales.

Ahora bien, si nuestra investigación se rehúsa a quedar inscrita en alguna de esas dos posiciones enfrentadas, resulta pertinente ahondar en este vínculo y explorar el entre medio o resto que resulta de tal diferencia. Por lo tanto, el ánimo que guía nuestra exploración no se dirige a dejar en evidencia la moderación, o la avidez avasallante de esta práctica política, sino más bien a indagar en los efectos ambivalentes que propicia, para en todo caso traer a la luz ciertos rasgos que resultan significativos.

También, es importante destacar que nuestra intención es acotada, porque tal como muestran los debates recientes, existen múltiples interpretaciones sobre el populismo, como también existen experiencias populistas heterogéneas para tener en consideración. ${ }^{1}$ De modo tal que, lejos de pretender llevar a cabo una exploración teórica y empírica exhaustiva de aquel vasto universo, nuestro interés se centra en ciertas intervenciones teóricas recientes y se ancla particularmente en uno de los

1 Como ha sido señalado, varias de estas interpretaciones reducen el fenómeno del populismo a experiencias históricas concretas, mientras que otras le atribuyen una especificidad teórica, válida para explicar diferentes casos en contextos históricos disímiles (Quiroga 2015). 
denominados populismos "clásicos". Es decir, para favorecer el entendimiento de este vínculo, nuestra apuesta pretende principalmente rescatar ciertos rasgos destacados del populismo, para de este modo explorar esa experiencia concreta que tuvo lugar durante el transcurso del primer peronismo en la Argentina de mediados del siglo pasado (1946-1955). Sin ánimos de polemizar con el carácter populista que se le atribuye (más bien, tomándolo por cierto), nos acercamos al primer peronismo a través de ciertos testimonios de la época (cartas y comunicaciones), con el interés de rastrear el modo en que el lenguaje de los derechos ciudadanos del nuevo régimen forjó la prosa y el devenir identitario de un sujeto popular. En ese recorrido, los espectros del populismo que rondan en varias de las producciones teóricas, se encarnan en una experiencia singular y es hacia esa forma de articulación precisa y acotada hacia donde se dirige nuestro análisis.

Por lo pronto, antes de dar paso a esa exploración, nos detendremos en los rasgos que otorgan cierta especificidad al populismo y que consideramos importante retomar para reflexionar en torno al vínculo que nos ocupa.

\section{UN VÍNCULO CONFLICTIVO Y ERRANTE}

Uno de los esfuerzos interpretativos más lúcidos para descifrar la especificidad del concepto de populismo ha sido el desarrollado por Ernesto Laclau a lo largo de sus obras (Laclau 1977, 2005; Laclau y Mouffe 1985; véanse también Canovan 1999; Mackinnon y Petrone 2010; Taggart 2000; Mazzuca 2013). En un intento por distanciarse de miradas peyorativas y esencialistas que otorgaron al populismo ciertas características propias derivadas de experiencias históricas particulares, Laclau enfatizó la dimensión discursiva de este fenómeno, y designó como populismo a un modo particular de articulación política que, como tal, se presenta como una posibilidad siempre presente de estructuración de la vida política. Este modo, o lógica política que subyace en el discurso populista, se define por la dicotomización del espacio social mediante la creación de una frontera interna entre el pueblo (los más débiles) y el orden existente, y por 
la presencia de un líder que constituye la unidad imaginaria del pueblo heterogéneo. Si como sostiene Laclau, el populismo se basa en una lógica política, antes que en un conjunto de ideas sustantivas, podemos deducir que, por un lado, este fenómeno puede atravesar un abanico amplio de experiencias políticas pertenecientes a contextos históricos muy diferentes e identificadas con corrientes ideológicas dispares (que van desde la izquierda, a la extrema derecha), y por el otro, que la cuestión de si un líder o régimen es populista no es una cuestión absoluta, sino de grado, y dependerá entonces de las diferentes lógicas que el líder o el régimen articule, de acuerdo con los contextos políticos en que opera (Laclau 2005). Este giro formalista resultó, entonces, en una ampliación del concepto de populismo, así como también en la apertura de nuevas sendas de interpretación (ahora desmarcadas del sesgo historicista y sustancialista), dispuestas a descifrar los vínculos de esta lógica política con los ordenamientos democráticos vigentes. ${ }^{2}$ Justamente, en esta senda interpretativa se encuentran (entre otros) los desarrollos teóricos de Gerardo Aboy Carlés y de Sebastián Barros. Para ello, nos detendremos en ambas argumentaciones, ya que encontramos en ellas ciertos lineamientos que pueden esclarecer la relación que nos interesa explorar entre populismo y derechos ciudadanos. ${ }^{3}$

Por su parte, Aboy Carlés define el populismo como "una forma específica de constitución y funcionamiento de las identidades políicas así como de relación con el resto de las identidades que componen el espacio comunitario" (Aboy Carlés 2016: 16). En esta forma de constitución identitaria están

2 Como se ha señalado, la construcción de un orden político populista y los desafíos que este proceso plantea para el sistema democrático liberal republicano, son escuetamente atendidos por Laclau. Privilegiando la dimensión rupturista de esta lógica política (y por tanto, desatendiendo su dimensión fundacional), el vínculo entre populismo y democracia permanece escasamente abordado por el autor (Panizza 2008; Aboy Carlés 2005).

3 Se ha señalado que, a partir de sus últimos desarrollos teóricos, el pensamiento de Laclau cae en una suerte de sinonimia entre política, hegemonía y populismo, que vuelve borrosa la especificidad de cada uno de estos términos. Barros y Aboy Carlés, entre otros varios autores, dirigieron sus investigaciones a indagar sobre las especificidades de cada uno de estos términos (Barros 2006; Marchart 2005; Stavrakakis 2004; Arditi 2010; Retamozo 2017). 
presentes dos dimensiones que, si bien no son exclusivas de este fenómeno, le otorgan al populismo ciertos rasgos específicos. Por un lado, una dimensión fundacional y rupturista, que involucra el trazado de una frontera que distingue entre un pasado repudiado y un futuro venturoso, y por el otro, una dimensión hegemonista, que aspira a la conciliación comunitaria; esto es, los lazos políticos que se conforman en torno al quiebre con un orden excluyente, reclaman para sí la representación del pueblo en su conjunto, dando paso a un colectivo del cual el antagonismo ha sido expulsado. Por consiguiente, la convivencia de ambas dimensiones en la constitución y funcionamiento de las identidades populares, genera tendencias opuestas -en la partición y en la representación unitaria de la comunidad-y por lo tanto, propicia tensiones y rasgos identitarios aparentemente contradictorios.

Así pues, para este autor, la especificidad del populismo estaría dada por los mecanismos particulares de negociación y procesamiento de la fuerza contradictoria que genera el doble ímpetu fundacionalista y hegemonista de esta forma de práctica política. El populismo, entonces, consistiría "en un movimiento pendular que agudiza las tendencias a la ruptura y las contratendencias a la integración del espacio comunitario, incluyendo y excluyendo a la alteridad constitutiva del demos legítimo; esto es, re-inscribiendo y borrando, a veces alternativa, a veces simultáneamente, su propia frontera fundacional" (Aboy Carlés 2016: 17). De tal modo, ese juego pendular toma la forma de una empresa regeneracionista que involucra una reconfiguración de los límites de la identidad popular emergente, de los que cuentan como opositores, y en definitiva del demos legítimo. Por cierto, la inestabilidad del demos legítimo resulta así un rasgo central para comprender la naturaleza de esta realidad sociológica-política; puesto que su redefinición constante es lo que permite el sostenimiento de la administración de esas dos lógicas contrapuestas, dirigidas a la ruptura y a la conciliación social. Precisamente, es allí donde -en términos del autor - reside la especificidad del populismo, manifiesta por la doble valía del término pueblo, como plebs y como populus. ${ }^{4}$

4 Respecto de la doble valía del término pueblo, Aboy Carlés retoma el concepto de plebs, introducido por Rancière, y el de populus, expresado en términos latinos. El 
Ahora bien, allí donde se aloja su especificidad, también se engendran las tensiones y conflictos del populismo con las democracias actuales y con sus formas institucionales. Aun cuando el movimiento constante entre plebs y populus introduce un elemento pluralista que aleja al populismo de las formas de administración autoritarias, su cercanía con la democracia liberal es ciertamente errante. Es decir, la constante inestabilidad del demos legítimo, resultante del juego pendular de inclusiones y exclusiones del adversario, propicia una forma de ciudadanía beligerante que se caracteriza no solo por generar "una marca de pertenencia comunitaria sino la siempre reeditada experiencia de una partición de esa comunidad" (Aboy Carlés 2016: 17). Así pues, las réplicas de la inestabilidad del demos repercuten en el ejercicio de los derechos ciudadanos, otorgándole un carácter de conquista frente a un enemigo que se beneficia a expensas de excluir a la identidad popular emergente. Precisamente, entonces, este aspecto beligerante somete el vínculo entre populismo y derechos ciudadanos a los avatares de los debates y combates políticos, y no lo libra de los riesgos de los "mecanismos represivos" que, de acuerdo con los vaivenes de opinión, pueden o no operar. Por lo tanto, el autor concluye que, en última instancia, el juego regeneracionista particular de cada experiencia populista determinará la posibilidad, siempre tensionada, de una convivencia más o menos respetuosa de los derechos y

primero de ellos hace referencia al pueblo como una parte de la comunidad —o más precisamente, la parte de los sin parte, quienes no entran en la cuenta, la multitud que hace barullo, los pobres-. El segundo refiere, no ya a una parcialidad, sino a quienes pertenecen al demos, es decir, al pueblo como conjunto de los miembros plenos de una comunidad dada. De aquí que plebs y populus nunca puedan permanecer idénticos a sí mismos. La tensión inerradicable entre ambos reside, como lo mencionamos, en que en un proceso fundacional, la plebs emergente, disputa la redefinición de los límites del demos y reclama para sí la representación del populus legítimo. Para un mayor desarrollo de esta tensión y doble valía, véase Gerardo Aboy Carlés (2007, 2013), Ernesto Laclau (1996).

5 Por elemento pluralista, Aboy Carlés se refiere a la posibilidad de múltiples e inacabadas representaciones de lo popular, y en definitiva, del pueblo, que el ordenamiento de tipo populista permitiría. Es decir, el populismo no conduciría a una representación uniforme y homogénea del pueblo, ya que, debido a la constante tensión entre plebs y populous, habría siempre lugar para la diversidad y multiplicidad (Aboy Carlés 2016). 
libertades de aquellos que son y no son adversarios políticos. Entonces, para Aboy Carlés no es posible establecer una caracterización general del vínculo entre el populismo y el ejercicio efectivo de los derechos ciudadanos de un régimen democrático. No obstante, sí es posible presuponer una tensa coexistencia; es decir, aun cuando el populismo implique el reconocimiento de nuevos derechos y de nuevos sujetos de derecho, no resguarda al orden político resultante de los espectros combativos de la plebs y de sus efectos disruptivos sobre el conjunto de las normas democráticas.

Por otra parte, en la misma huella de inspiración laclausiana, Sebastián Barros retoma la tensión entre la plebs y el populus que señala Aboy Carlés para caracterizar el populismo, pero incorpora otro rasgo no menor para los fines de nuestro análisis (Barros 2006a, 2011, 2012). En un texto reciente, el autor propone distinguir analíticamente dos procesos políticos que comúnmente han sido homologados en la caracterización del populismo; por un lado, la emergencia de las identificaciones populares, y por otro, los procesos de articulación política populista (Barros 2013). Según Barros, las identificaciones populares suponen configuraciones identitarias distintivas que es preciso dilucidar, como también diferenciar de otras formas de identificación política. Las identidades populares implican la conformación de demandas que irrumpen tensionando los límites comunitarios y poniendo en cuestión la definición de quienes forman parte efectiva del espacio de representación. Uno de los rasgos más distintivos está dado por su imprecación en el orden establecido, mediante la visibilización de su voz como legítima y el reclamo de su condición de miembro pleno en la vida comunitaria. Su otro rasgo distintivo refiere a la presentación que los sujetos emergentes hacen de sí mismos como víctimas particulares de un daño ocasionado por el orden comunitario, "es en cuanto víctimas del daño que esa comunidad ha ejercido y ejerce sobre ellas que la demanda impreca" (Barros 2013: 46). También las distingue la igualdad que presuponen en la capacidad para tomar la palabra, y en la obligación de ser escuchados por la comunidad.

El devenir de las identificaciones populares no debe ser confundido analíticamente con el proceso mismo de articulación populista, porque tal 
como sugiere el autor, aquellas pueden o no ser articuladas de acuerdo con esta forma de construcción política, dependiendo de la relativa estructuralidad en la que emergen (Barros 2013: 42-56).

Sin embargo, también señala que este modo de articulación sólo es posible y opera sobre la proliferación de identificaciones populares. Precisamente, son los efectos sobre la representación comunitaria, provocados por este tipo de identidades, lo que permite descifrar la tensión entre la ruptura fundacional y la reconciliación comunitaria adjudicada a los populismos. En esa dirección, advierte sobre las dislocaciones que la constitución de este modo de identificación genera sobre los límites de la comunidad, "provocando sus desplazamientos, tanto en relación con su extensión o restricción como en relación con la distribución de lugares sociales que esos límites demarcan" (Barros 2013: 49). De este modo, las identificaciones populares instituyen un litigio fundamental que divide en dos a la comunidad política, mediante la creación de una frontera interna en lo social que opera sobre los límites del demos legítimo. Por lo tanto, la dimensión fundacional del populismo adquiere una nueva significación a partir de los efectos desestructurantes que provocan las nuevas identidades populares. Así pues, estas identificaciones intervienen sobre la tensión entre la plebs y el populus, por cuanto aquellas partes que no cuentan como legítimas en la definición de lo común de la comunidad, se salen de su lugar y devienen subjetividades heterogéneas que demandan por una ampliación -siempre conflictiva, del demos legítimo. En efecto, sobre esas nuevas subjetividades y sobre sus efectos en el espacio de representación de la vida comunitaria, opera la articulación populista.

Por tanto, para Sebastián Barros la especificidad del populismo va más allá del mecanismo negociador de la tensión entre fundacionalismo y hegemonismo planteado por Aboy Carlés. En sus términos:

No basta con señalar esta tensión [entre la parte y el todo]. Las partes a las que nos estamos refiriendo tienen un carácter específico, son partes que suponen la partición de la vida comunitaria en dos a partir de la creación de una frontera interna a lo social [...] Por lo tanto, el trabajo hegemónico, cuando se pone en juego este tipo de identificaciones, es doble. Por un lado, debe operar sobre la tensión entre la parte y el todo; por el otro, debe 
operar sobre esa frontera interna en cuanto límite de la vida comunitaria. Este doble trabajo tendrá como efecto una nueva representación de la comunidad legítima (Barros 2013: 53).

La introducción de este rasgo subjetivo en la caracterización del populismo ofrece nuevas posibilidades para pensar el vínculo entre este tipo de lógica política y los derechos ciudadanos. Las identificaciones populares presuponen la igualdad en la capacidad de tomar la palabra y formar parte legítima de las decisiones de la vida comunitaria: una igualdad negada por el demos que es presentada en términos de un daño. Es decir, es reclamando un derecho que no tiene pero que tiene, que el sujeto popular, en nombre del daño ocasionado por la comunidad sobre él, reclama para sí la representación plena de la vida comunitaria. De esta manera, Barros complejiza el modo a través del cual se ha contemplado el vínculo entre el populismo y la ampliación de la ciudadanía. Tal como venimos destacando, la expansión de derechos no solo involucra la inclusión de una parte antes excluida y ahora reconocida, y por tanto amparada por la civilidad, sino también comprende un proceso de subjetivación política que forma parte inescindible de la tensión entre la plebs y el populus. Este proceso de subjetivación reactualiza la disputa respecto de quienes son contados como miembros plenos del demos legítimo, a la vez que somete a verificación los escenarios en donde los derechos son válidos y en donde no los son. Por consiguiente, los nuevos sujetos de derechos, haciendo eco de los señalamientos de Rancière, son sujetos políticos que enlazan las relaciones de inclusión y exclusión y que, en momentos de disenso, asumen la calificación paradójica de ser y no ser parte del común de la comunidad (Ranciére 2004)

En coincidencia con Aboy Carlés, entonces, para Barros el populismo también tensiona la esfera de los derechos ciudadanos. No obstante, esta tensión adquiere un matiz diferente. Para Aboy Carlés, aquello que le otorga cierta especificidad al populismo también promueve una tensa coexistencia con las libertades y los derechos ciudadanos. La forma beligerante que adopta la ciudadanía, a partir del movimiento pendular entre la ruptura y la reconciliación del orden comunitario, tensiona la esfera de los 
derechos existentes, otorgándole un carácter de conquista a los procesos de ampliación de ciudadanía y de reconocimiento de nuevos derechos por parte de los antes excluidos, de allí que, en términos de este autor, el populismo no pone el orden político al resguardo de los espectros combativos de la plebs y de sus efectos y riesgos disruptivos sobre el conjunto de las normas democráticas. Por otra parte, para Sebastián Barros, el vínculo errante entre populismo y derechos se origina en la inscripción misma de un litigio irresoluble respecto de quiénes cuentan como parte legítima de la comunidad. Esto es, las identificaciones populares irrumpen en el populus, desplazando los límites del demos y alterando la distribución de los lugares legítimos en el espacio de representación, y es justamente en esa irrupción/alteración que se pone a prueba el alcance y las posibilidades mismas del ejercicio de las libertades y los derechos ciudadanos. Por consiguiente, el populismo, en tanto lógica que opera sobre el terreno movedizo de las identificaciones populares, socava el semblante de una esfera de derechos, ya siempre consagrada, despejando a su paso la espesura de su acontecer arbitrario y de su alcance limitado.

Entonces, recapitulando lo dicho hasta aquí y retomando nuestra primera intención de eludir el embrollo ocasionado por posiciones contrapuestas sobre el vínculo entre el populismo y los derechos ciudadanos, los señalamientos de Aboy Carlés y Barros allanan el camino hacia un mejor entendimiento y resultan, a la vez, auspiciosos de nuevas exploraciones sobre el devenir de la praxis ciudadana en experiencias populistas. Por cierto, inscribiéndose en el giro discursivo de Laclau, las reflexiones de ambos autores nos dejan al resguardo de un conjunto de ideas sustantivas y de atributos necesarios que desembocan en la calificación de los populismos como intrínsecamente autoritarios o como inexorablemente democráticos. En cambio, para indagar sobre las fisuras que atraviesan el binomio populismo-democracia, desplazan nuestra mirada hacia la tensión que el doble ímpetu fundacionalista y hegemonista de esta práctica políica genera sobre el ordenamiento social. Es precisamente esa tensión y los modos de gestionarla, lo que asegura al populismo una dimensión pluralista que ciertamente lo aleja, por una parte, de los ordenamientos políticos 
autoritarios, y por la otra, de la supuesta incompatibilidad con las instituciones propias de las democracias republicanas. Asimismo, el tipo de identificaciones que habita el populismo y lo hace posible, previene el estrechamiento del desacuerdo democrático, con lo cual pone a prueba y visibiliza las fronteras porosas y maleables que limitan el ámbito de los derechos consagrados.

Justamente, si entre el populismo y el ejercicio de los derechos ciudadanos no habita una hostilidad inexorable, sino más bien una tensa coexistencia, este tipo de intervenciones auspician nuevas sendas de exploración en relación con las formas de ciudadanía que se despliegan bajo aquellos ordenamientos políticos, pues se habilitan y promueven nuevos interrogantes respecto de las modalidades particulares que adopta esa tensa convivencia, y sobre sus efectos subjetivos. O en otras palabras, si la beligerancia y el conflicto aparecen como aspectos distintivos, bajo escenarios de impronta populista, vale preguntarnos qué aspectos distinguen a una modalidad ciudadana de tipo beligerante de otras, y qué configuración identitaria propicia esta tensión, cuando se convierte en un rasgo propio del discurso hegemónico. Precisamente, a modo de esbozo de este tipo de abordaje, en la próxima sección exploramos la experiencia del primer peronismo, en particular enfocándonos sobre sus efectos, en tanto discurso populista que hizo de la justicia social y los derechos sociales el significante nodal de su proyecto político. Lo haremos, como señalamos en la introducción, a través del análisis de ciertos fragmentos de vida que se encuentran en la correspondencia entre mujeres y hombres de a pie y las autoridades políticas de la Argentina peronista.

TRAS LOS RASTROS DEL SUJETO CIUDADANO

EN LAS CARTAS A PERÓN

La convivencia conflictiva del peronismo con la esfera de los derechos ciudadanos emergió en el mismo momento de su surgimiento y acompañó al régimen en el transcurso de su devenir. El ejercicio efectivo de los derechos ciudadanos sufrió modificaciones que no sólo se recono- 
cieron en la reconfiguración del universo de destinatarios y en la ampliación de ciudadanía que ello trajo aparejado, ${ }^{6}$ sino también, en la proliferación de tensiones y conflictos sociales que encontraron en el Estado una nueva superficie de inscripción. Como hemos destacado en trabajos anteriores, la proclamación e institución de un decálogo de nuevos derechos sociales, implicó beneficios materiales y simbólicos, pero también trajo consigo un nuevo lenguaje que puso en cuestión los usos y sentidos alrededor de los derechos de los individuos que habían dominado el imaginario político hasta entonces (Barros 2014). En efecto, la expansión de derechos versó sobre un lenguaje político que apeló a la justicia social y a la defensa de los derechos de los trabajadores, en oposición a un pasado signado por la exclusión y la desigualdad en lo social, lo económico y lo político de los sectores populares. Los derechos del peronismo encontraron, así, su anclaje en la radical negación de la experiencia pasada de desigualdad y exclusión, adquiriendo una impronta igualitaria e inclusiva que se proponía reparar aquellas injusticias del pasado y del presente cometidas sobre un sector que no era parte de la comunidad. Los nuevos derechos eran la conquista de los pobres, de los miserables, de los excluidos, de los que menos tienen, de los así llamados esclavos. Bajo esos nombres "impropios", los sujetos serían capaces de reclamar por los derechos por venir. De este modo, el lenguaje de derechos del peronismo resultó constitutivo, tanto de la frontera interna que dividió en dos a la comunidad (peronistas y antiperonistas), como de la forma que adquirió el antagonismo durante aquella experiencia populista.

El uso de este nuevo lenguaje y su materialización en una serie de reformas institucionales y sociales, promovió nuevos beneficios, pero, sobre todo, nuevas atribuciones para participar activamente en diferentes dimensiones de la vida socioeconómica y política de entonces. Justamente, sobre esa vivencia popular inédita, se forjó una nueva matriz subjetiva que

6 En general, la literatura sobre la política social en Argentina ha coincidido en sostener que el peronismo clásico implicó una extensión cuantitativa y cualitativa significativa de la intervención del Estado en materia social. Véanse Torre y Pastoriza 2002; Lvovich y Suriano 2006; Berrotarán 2004. 
sostuvo al peronismo como movimiento político y sobre la que se moduló la praxis ciudadana que prevaleció durante el periodo. Al respecto, son frecuentes los testimonios de sujetos peronistas que apelan a la metáfora del "despertar del pueblo dormido", con el fin de definir la experiencia que significó la irrupción del peronismo para los sectores populares y para referirse a los cambios en los modos de percibirse, proyectarse y actuar en el nuevo ordenamiento social.

Por lo anterior y con el empeño de ir tras las huellas de la dimensión subjetiva de aquella experiencia, recurrimos a un acervo documental escasamente explorado por la historiografía, como es el conjunto de cartas que hombres y mujeres de a pie enviaron a las autoridades políticas durante el primer y segundo gobierno de Perón. ${ }^{7}$ En otro lugar, con mayor detenimiento, hemos indagado sobre el valor historiográfico de la carta como fuente, así como también incursionado en los desafíos epistemológicos y metodológicos que plantea para el análisis político. ${ }^{8}$ Aquí solo vale aclarar

Estas cartas, enviadas desde el inicio del primer mandato, pero en mayor medida a partir del llamado que el mismo presidente Perón hiciera ante el anuncio de su Segundo Plan Quinquenal en 1951, provinieron de diferentes localidades y sectores sociales del país, respondiendo a muy distintas motivaciones: intervención estatal en materia de obra pública (escuelas, ampliaciones de servicios básicos, caminos, universidades), consideraciones sobre la realidad local y nacional, exigencias sobre el mundo del trabajo, acusaciones y denuncias sobre irregularidades en la función pública, elaboraciones y propuestas de proyectos científicos y tecnológicos, reflexiones filosóficas de diversa índole, y las más variadas manifestaciones de quejas y penurias, como así también de anhelos y aspiraciones. Gran parte de esa correspondencia se encuentra actualmente archivada y clasificada en el Archivo General de la Nación y en algunos archivos históricos provinciales del interior del país.

8 Cabe destacar que entre 1951 y 1952, llegaron alrededor de 70000 cartas a las diferentes dependencias del Estado, de las cuales actualmente se conservan unas 19000 en el Archivo General de la Nación. Las solicitudes recibidas fueron clasificadas en carpetas que registraban los siguientes datos: "iniciador" (que podía tratarse de individuos particulares o colectivos), "tema" (la demanda propiamente), "materia" (área a la que la demanda remitía: educación, obras sanitarias, obras públicas, etc.), "ministerio" (al cual dependía su evaluación y realización) y, finalmente, "provincia o territorio" de procedencia. Las cartas fueron leídas y clasificadas por varios ministerios, y muchas de estas obtuvieron su respuesta. Nuestro trabajo se propone analizar las misivas, recuperando la dimensión subjetiva que se manifiesta en las demandas concretas, en especial nos interesa dilucidar el modo de identificación política que se gestó entre 
que rescatamos las prácticas epistolares en tanto prácticas significativas de una subjetividad política susceptible de rastrearse desde el trazo de la palabra escrita. En las cartas se cuelan las voces populares y fragmentos de vida de una época, lo que permite merodear en una subjetividad que no se manifiesta en otro tipo de materiales, ni en entrevistas posteriores. No se trata de una fuente "más transparente" que otras, pero sí de un medio destacado que habilita un acercamiento a la dimensión subjetiva hasta ahora sólo asociado con las narrativas de la historia oral. Por obvio que parezca, aclaramos que el registro analítico del periodo al que permite acceder la carta, difiere de aquel que propone un recorrido obligatorio por documentos oficiales y discursos de las principales figuras y referentes. Este último, si bien imprescindible para comprender el imaginario instituido por el régimen, no agota los senderos posibles para acceder a la experiencia política del primer peronismo. Como sugiere Eric Hobsbawm, hasta las mejores fuentes iluminan solo algunos aspectos de los procesos históricos (Hobsbawm 2002). Así es como, cual fotografía bajo cierta luz y desde cierto ángulo, la exploración de las cartas habilita un abordaje descentrado y disperso que ilumina los discursos públicos, pero, sobre todo, deja ver ciertos modos en que los hombres y mujeres de a pie habitaron el mundo que el peronismo les ofrecía, ejerciendo sus derechos y dando forma a su condición ciudadana. En esta ocasión, nos remitiremos a tres cartas que reivindican derechos desde experiencias populares diferentes.

Comencemos con una carta escrita por María Isabel, de la localidad de Monte Buey, provincia de Córdoba, dirigida a Eva Perón, donde le solicita que interceda por un problema de pago en torno a su cosecha de trigo:

Estimable Presidenta, la saludo con toda la seremida mia y la de mi ijo muy atentamente buena señora le pasare a desirle mis cosas que es un poco importante es por unas 260 cuadra de trigo a razón de $3 \$$ por cuadra y no por dia como quería el señor Leonardo Martin a razón de $15 \$$ por dia asi querro señora Eba si puede hacer la carida de obrar como Presidenta

los sectores populares y el régimen peronista. Para un argumento detallado del uso y los recursos metodológicos empleados en el análisis de estos documentos epistolares en nuestro trabajo, véase Mercedes Barros et al. 2017. 
que me aga pagar la cosecha yo por lo meno qreo por lo tanto que etamo hapoyado.

A la par de uste doña Eba de Peron somo peronista hasta la muerte por lo tanto le pido de favor que me aga el gran serbisio que la tendo por una buena presidenta que obra por los pobre (Archivo de Gobierno de la Provincia de Córdoba, 1948, Solicitudes diversas, tomo I, folios 564 y 565).

Sin demasiadas adulaciones, María Isabel, en su carta, apela a la figura de Eva para enunciar su petición. La protagonista se identifica con el discurso del gobierno "como peronista hasta la muerte", y hace uso del juego metonímico de términos que se establecía en la configuración discursiva peronista entre los pobres y Eva, entre Eva y Perón, y entre Perón y el gobierno peronista y el Estado. En la conjunción de esos discursos disponibles, la mujer que escribe se sujeta a las palabras de aquellas figuras protagónicas del peronismo, y solicita lo admitido y esperable en un orden que favorece a los que menos tienen. No obstante, no se agota allí el proceso de identificación. La ambivalencia que recorre el proceso identitario se cuela en las palabras de María Isabel:

yo creo que a una pobre siega como yo me valgo en uste señora porque estoy habatida ya de la gran pobresa que me encuentro espero señora Eba de Peron que obre como presidenta de la Republica Argentina que la única dama que me ba a lluda señora Eba Duarte de Peron me buelbo a explicar e pedido.

Recurro a uste unas cuantas beces haver si me puede pagar la cosecha por que el hotro dia yo misma able con el señor Leonardo Martin y me dijo fuera hadonde quería yo que el no hiba a pagarme y dijo que me podía quejar a dies Peron el no iba a pagar a nadie porque la plata del no se la cita nadie asi espero señora que nosotro los peronista le pregunto. si resibio la copia que le mande a uste señora por que asta ahora no e tenido contesto y se la mande a sus manos propias aber si me ase o me manda algun alluda por que no puedo trabajar por que soy siega y hadema tengo un ijo no es ta chico ni esta grande tiene 14 años cumplidos y aca en este pueblo no se consige trabajo ... y asi pasamos la bida sin domisilio sin techo para dormir si ciera tirado a la calle co una bola que la patean y la pisan asi como nosotro señora Eba Duarte de Peron me extraña que una peronista al fabor de Peron y Ebita que rode por la calle como una bola y como un fulbo que lo patean y no le tiene lastima de que se rompa o si piche y si se 
deja patiar es por que no tiene defensa ninguna asi somo nosotros señora Ebita de Peron iasi qreo que me podría alludarme a una pobre tirada a la calle! (Archivo de Gobierno de la Provincia de Córdoba, 1948, Solicitudes diversas, tomo I, folios 564 y 565).

En el transcurrir narrativo, la petición de María Isabel deviene una exigencia. Así es como, iterando elementos de un lenguaje político que pretende develar la injusticia, María Isabel se apropia de la ambivalencia que auspicia el peronismo en su tránsito recurrente entre ser parte y ser todo para denunciar el estado de daño en el que aún vive. Denuncia su "no lugar" como "bola que rueda" de un lado para otro, y, en este último sentido, también reafirma que la injusticia continúa bajo el peronismo, aun siendo ella una peronista "hasta la muerte". Como viuda y madre de la Nueva Argentina, es merecedora de una seguridad y protección social del Estado, que se convierten en un derecho a la luz de la situación laboral en la que se encuentra. Entonces, desde su posición heterogénea, María Isabel pone en cuestión los límites y el alcance de la inclusión que promueve el peronismo; esto es, construye una escena de verificación de la igualdad en la que, haciendo uso de la legitimidad que le confiere ser peronista, denuncia su situación de daño todavía presente y exige reparación. Así, asumiendo esa situación de paradoja en la que es - como trabajadora peronista - y no es parte efectiva - como bola que rueda - de la vida comunitaria, tensiona el modo en que el peronismo opera sobre la frontera interna de lo social, otorgando nuevos derechos y proclamando nuevos destinatarios. La presentación que la mujer realiza de sí como trabajadora peronista, pero también como pobre, reactualiza el litigio que parte en dos el orden social. Por lo tanto, María Isabel, mediante la descripción de sí como "una bola que rueda de un lado al otro", metaforiza el intersticio entre los dos mundos en los que habita: el mundo en el que es parte de la vida comunitaria y el mundo en el que no lo es. Mediante su denuncia, esta mujer lleva al límite a la autoridad oficial y configura un escenario en el que el otorgamiento de nuevos derechos no sólo supone una dimensión de conquista sobre un otro responsable de su estado de daño, sino también de la exigencia hacia Eva Perón. Así, la "denuncia y exigencia" 
aparecen como aspectos distintivos de la modalidad subjetiva que se despliega en el material escrito.

Procedamos ahora a registrar la carta de una costurera, Angsea Corral, de Santa Rosa, La Pampa, enviada a Perón:

Habiendo escuchado y leído vuestro mensaje al pueblo trabajador pidiendo nuestra colaboración para la preparación del Segunda Plan Quinquenal, y yo en mi carácter de Secretaria General del Sindicato de Obreros Sastres y Costureros y Afines Filial P.O.N.I.V.A. en Santa Rosa, Provincia de la Pampa:

Me permito mencionar a V. E. mi aspiración que abrigo hace varios años, ya que es el deseo unánime de todos mis compañeros, de que se realice en una forma económica como la que detallo en el presente proyecto de la creación de un taller de costura.

Pero para que esto sea realidad, más pronto necesitaríamos que se nos otorgara un préstamo o un crédito para la primera compra de las telas. Dicho préstamo lo saldaríamos en cuotas a medida que se vaya trabajando y vendiendo la mercadería.

Si bien este sindicato tiene en víspera de poner en La Pampa a dos convenios que de allí obtendría una buena suma de dinero, por corresponderle al Sindicato el aumento del primer mes, pero esto tardará algo, además "como toda entidad" aspiramos a la CASA PROPIA del sindicato, entonces dejaríamos estos haberes en depósito.

Por otra parte yo pienso que es una buena forma de combatir a la clase patronal con la competencia mediante talleres propios, de los Sindicatos que allí se efectúe la producción de lo que nosotros mismos consumimos.

También sería muy necesario y casi indispensable pusieran a la venta máquinas de coser a un precio económico y pagaderas en cómodas cuotas con derecho aquellas personas que saben trabajar y que puedan garantizar el pago con su trabajo.

Luego pongo a consideración otro punto de vista "y esto pido perdón por la forma de pensar" que la obrera u obrero que trabajara para un taller de un sindicato, el día que su edad avance o por impedimento físico no pueda trabajar más, que como tal pasara automáticamente a pertenecer De los Derechos de la Ancianidad quedando así solucionada su jubilación.

Dios guarde a vuestra Excelencia Saludamos a Ud. Atentamente (AGNST, caja 668).

Reconociéndose en aquel pueblo trabajador al que se dirigía Perón, Angsea Corral toma la palabra y responde a la interpelación del manda- 
tario. Pero, nuevamente, aquí es relevante señalar el modo particular en el que se produce aquella respuesta e identificación con las palabras del líder político. La protagonista teje su propuesta recurriendo a ciertos elementos convencionales que circulaban en el discurso oficial sobre la necesidad y el rol protagónico del sindicato en la defensa de los trabajadores, y equipara el sindicato de obreros costureros y sastres con otros sindicatos de trabajadores, reclamando "como toda entidad" su legítimo lugar. Esta función admitida del sindicato es suplementada por la creación de un taller propio y por la posesión de las propias maquinarias para la producción. De esta manera, Angsea recurre al discurso oficial, pero para someterlo a nuevas articulaciones que desplazan y amplían el significado de las organizaciones gremiales y de los derechos laborales. Por cierto, esta dimensión articuladora y productora de nuevos significados se manifiesta claramente en el último tramo de la carta, cuando la solicitante pide algo que ella misma supone no debería pedir ni pensar: derechos de la ancianidad para los obreros y obreras del sindicato que preside. El uso de comillas y las disculpas anticipadas, "y esto pido perdón por la forma de pensar", denotan un reclamo que "excede" lo "admitido y concebido" dentro del marco vigente, y que en cierta forma se presenta - de acuerdo con el propio tono del relato- como desmesurado respecto a lo planteado por Perón. Sin embargo, y pese a esta desmesura, la mujer se siente capaz de pensar y demandar, poniendo de manifiesto una modalidad subjetiva que no solo reclama, sino que también desobedece, forzando de modo tal y de forma irreverente las palabras del líder. A la vez, en su desobediencia, se deja ver su deseo y esperanza de una distribución más igualitaria de bienes y lugares comunitarios.

La carta enviada a Perón por un tambero muestra también este desplazamiento de la frontera de lo deseable en la Argentina peronista:

Accediendo al llamado que formula a todos los trabajadores argentinos, me tomo el derecho de dirigirme a Ud., como obrero cuyo único propósito es que una vez se nos escuche y se que de recibir usted, esta carta, muy pronto nuestros sueños serán convertidos en realidad, porque así debe ser; Usted que tanto ha hecho por el bien de nuestra patria, Ud. que ha favorecido a todos los trabajadores Argentinos, sé que ahora pondrá todo su 
empeño para favorecer a todos los tamberos porque hasta el día de hoy, el único trabajador que no ha sido favorecido somos nosotros, los tamberos (AGN-ST, caja 669).

Luego de una descripción extensa de sus condiciones laborales - que por cuestión de espacio no podemos transcribir en el texto- el protagonista le pide a Perón que "reflexione bien"; además, sostiene al respecto: "y no dudo que hará justicia a nuestro trabajo". Luego continúa:

Nosotros que no tenemos días de fiesta, nosotros que no tenemos aguinaldo, ni lo pedimos tampoco, queremos que se paguen nuestros esfuerzos como se les paga a miles de obreros... Nuestro patrón José Nicola dueño de casi 200 Has. y no se cuantos animales, nos tiene en una pieza miserable, un dormitorio y una pieza donde duermen nuestros hijos hace 4 años y sin tener aunque sea un reboque de barro, ni tenemos la dicha de contar con un baño. Ahora que Ud pide la colaboración nuestra para el Segundo Plan Quinquenal, ahí tiene la nuestra y quedamos todos los tamberos esperando que Ud. Excmo. Señor Presidente nos de una ley que nos favorezca (AGN-ST, caja 669).

En esta carta vemos cómo el tambero está demandando más de lo que está presente en la nueva Argentina del peronismo, desplazando la misma noción de justicia y derechos sociales del discurso oficial, a terrenos no contemplados y extraños de las definiciones oficiales. Recurriendo a un lenguaje de derechos, el tambero construye una escena de verificación de la igualdad, que vuelve visible la brecha que existe entre la interpelación ideológica del peronismo, que identifica a los trabajadores como sujetos de la justicia social y de los derechos sociales, y su experiencia concreta y singular de injusticia y desigualdad. Ahora bien, en la descripción de esta experiencia, el tambero desplaza los límites de la alteridad y el daño definidos por el discurso oficial. La situación de miseria en la que vive junto con su familia cobra sentido a la luz de una relación laboral que no es parte de los nuevos marcos regulatorios que ofrece el peronismo. En este sentido, la carta pone a prueba la efectividad y el alcance de los derechos consagrados, denuncia el sistema de relaciones sociales desiguales, de subordinación y de patronazgo en el que se halla inmerso, y reclama por la reparación 
de la injusticia y el maltrato. Así, el remitente deja ver la heterogeneidad hacia el interior del peronismo, reescribiendo la tensión en la esfera de los derechos ciudadanos. En el trazo de su palabra escrita, la denuncia, la desobediencia y el deseo, se manifiestan como aspectos distintivos de una subjetividad en ciernes, inmune a los límites del discurso hegemónico.

En esta y en otras tantas peticiones enviadas a Perón y a Eva durante el periodo, nos interesa destacar cómo en la escritura se delinean procesos subjetivos particulares que convergen en la manifestación de un sujeto popular que, sin proponérselo, cuestiona y visibiliza los límites de representación del orden y trae al ruedo elementos anteriormente impensables. En ese terreno movedizo de lo impensado, hombres y mujeres se apropian de los derechos otorgados y de las nuevas atribuciones y lugares que ello les confiere en el orden social, haciendo de esa apropiación un ejercicio de ciudadanía activa y parte constitutiva de su lazo de identificación con el peronismo. En este sentido, lo que podemos apreciar en estas cartas es la compleja y tensa relación del sujeto con los derechos bajo el peronismo: un sujeto que si bien goza y se sujeta a los nuevos derechos otorgados, en y a través de aquel lenguaje también denuncia, desobedece y sueña. De este modo, entonces, fuerza los límites de los derechos ya consagrados e instituidos, reclama los que están por venir y lleva hacia nuevos escenarios imprevistos la tensión que el peronismo produce sobre la esfera de los derechos y que cuenta como parte legítima del común de la comunidad.

\section{PALABRAS FINALES}

A partir de la centralidad que adquirió el debate en torno al concepto de populismo dentro de las ciencias sociales en los últimos años, a lo largo de este artículo nos propusimos abordar uno de los aspectos de este debate: el vínculo entre el populismo y los derechos ciudadanos. Para esto repusimos las intervenciones del giro discursivo, y mostramos la importancia de pensar el populismo como una lógica política que pondera una tensión 
y que opera sobre cierto tipo de identificaciones populares. Estos rasgos habilitan una nueva mirada sobre este vínculo que nos preocupa, a la vez que dirige nuestra atención a una dimensión subjetiva no siempre valorada en los estudios historiográficos sobre el periodo. La exploración de las cartas del peronismo permite un acercamiento a esa matriz subjetiva que sostuvo al peronismo, en tanto movimiento político, y sobre la cual se moduló un modo de ser ciudadano que resulta significativo para pensar en torno a la relación entre el populismo y los derechos ciudadanos.

Como pudimos apreciar, al menos someramente en las cartas de la Argentina del primer peronismo, los protagonistas inauguran espacios de acción política que, a la vez que involucran un distanciamiento con el discurso hegemónico, ponen de manifiesto una forma de subjetividad que se aleja de aquel sujeto pasivo, adoctrinado y maleable que muchas veces evoca la literatura especializada. Los remitentes de las solicitudes y reclamos, no solamente confrontaban la inscripción de derechos con situaciones de negación, sino también entrecruzaban un mundo donde esos derechos eran válidos con un mundo donde no lo eran, y donde las relaciones estaban aún libradas al dominio discrecional de la riqueza, de la tradición, de la religión, de las costumbres y del patronazgo. La argumentación del tambero pone en escena la doble relación de inclusión y exclusión que se inscribe en su condición de trabajador de la Argentina oficial y en su condición de tambero olvidado y explotado, y es justamente en ese interludio que toman protagonismo la denuncia, la desobediencia y el deseo, como modalidades en torno a las cuales adquirió forma y contenido el ejercicio efectivo de los derechos ciudadanos.

Por lo tanto, resulta pertinente señalar que aun cuando la reconfiguración de los límites del demos del peronismo no careciera de efectos beligerantes, que pudieran desembocar en el aumento de los niveles de conflictividad social (Groppo 2009), consideramos que no se agotan allí sus repercusiones y tampoco se convierten en el rasgo distintivo de este ordenamiento político. A propósito de esto último, y a partir de nuestra exposición, uno de los aspectos más sobresalientes que nos interesa destacar versa sobre cómo el despliegue de un nuevo lenguaje de derechos 
tensionó irreparablemente el ejercicio de la ciudadanía, y afectó la relación que los ciudadanos establecieron con el Estado y sus instituciones. Como vimos a lo largo de la última sección, en y a través de aquel lenguaje de derechos, se forjaron múltiples escenas de verificación, abriendo camino a una modalidad subjetiva que, lejos de sujetarse a los derechos ya consagrados, reedita la disputa en torno a los derechos por venir. Asimismo, este nuevo léxico de disputa adquirió un carácter constitutivo en el lazo identificatorio que sostuvo esa modalidad subjetiva con los líderes políticos y con el Estado. Como hemos podido apreciar, las cartas de la argentina peronista pusieron en escena una y otra vez ese lugar protagónico que los derechos ciudadanos jugaron en la conformación de aquella identificación, y en la configuración de un imaginario en torno al rol estatal.

Finalmente, un señalamiento acerca de cómo el lenguaje de derechos del primer peronismo habilitó, tanto la percepción de un presente que se diferencia y opone a un pasado de daño, como también a la posibilidad de un futuro esperanzador. Esto es, posibilitó la proliferación de deseos que se proyectaron e inscribieron en ese porvenir promisorio. En las palabras de estos hombres y mujeres antes citados, se asoma una crítica que manifiesta el límite del ordenamiento vigente, y que, asumiendo un lugar de irreverencia hacia el interior del peronismo, perpetúa la tensión que el populismo produce sobre los derechos ciudadanos y reactualiza el contenido de la frontera antagónica trazada por la articulación hegemónica. De aquí que el ejercicio de nuevos derechos habilite despertares a nuevas posibilidades y pensamientos, y sobre todo de nuevos deseos que encuentran en el Estado un lugar donde alojarse y demandar reparación. En consecuencia, la articulación populista peronista propició la conformación de una matriz de subjetividades que, arrogándose la capacidad de denunciar, desobedecer y desear, sostuvieron a esta formación política, a la vez que la pusieron a prueba, visibilizando los límites porosos y arbitrarios de los derechos consagrados. De allí que reflexionar sobre la tensa coexistencia entre el populismo y el ejercicio de los derechos ciudadanos en la experiencia del primer peronismo, implica pensar en la reapropiación que 
realizaron los sujetos peronistas de dicha tensión y en los nuevos modos de reconocimientos de sí y de la realidad que devinieron de ello.

BIBLIOGRAFÍA

ABOy CARlÉS, GeRARDO. "Populismo y democracia en la Argentina contemporánea. Entre el hegemonismo y la refundación”. Estudios Sociales 28 (2005): 125-149.

. "La democratización beligerante del populismo". Debate 12 (2007): $47-58$.

- "De lo popular a lo populista o el incierto devenir de la plebs". Gerardo Aboy Carlés, Sebastián Barros y Julián Melo. Las brechas del pueblo: reflexiones sobre identidades populares y populismo. Buenos Aires: UNDAV, 2013. 17-40.

"Populismo y democracia liberal. Una tensa relación". Identidades 10 (2016): 1-22.

AbTs, Koen y Stefan Rummens. "Populism versus Democracy". Political Studies 55.2 (2007): 405-424.

Alegre, MarCelo. "Populismo y derechos humanos: iAgua y aceite?". 2016. Artículo en línea disponible en https://aw.yale.edu/system/files/ area/center/kamel/sela16_alegre_cv_sp.pdf (Consultado el 15 de febrero 2018).

Arditi, Benjamín. "Post-hegemonía: la política fuera del paradigma postmarxista habitual". Heriberto Cairo y Javier Franzé (comps.). Política y cultura. Madrid: Biblioteca Nueva, 2010. 159-193.

BARROS, MERCEDES. "Los derechos en el primer peronismo, desafíos y rupturas". Identidades 1 (2013): 18-33.

"Derechos que sujetan, sujetos de derecho bajo el primer peronismo". Estudios Sociales 47 (2014): 93-128.

- et al. "Las huellas de un sujeto en las cartas a Perón: entre las fuentes y la interpretación del Primer Peronismo". Fuentes y Archivos 7.7 (2017): 234-260. 
BARROS, SeBASTIÁN. "Inclusión radical y conflicto en la constitución del pueblo populista". Confines 2/3 (2006a): 65-73.

. "Espectralidad e inestabilidad institucional. Acerca de la ruptura populista". Estudios Sociales 16 (2006b): 145-162.

. "Identificaciones populares, populismo y democracia". Nuevo Topo 8 (2011): 21-34.

- "La presencia obnubilante del populismo". Utopía y praxis latinoamericana 17 (2012): 39-52.

"Despejando la espesura. La distinción entre identificaciones populares y articulaciones políticas populistas". Gerardo Aboy Carlés, Sebastián Barros y Julián Melo. Las brechas del pueblo: reflexiones sobre identidades populares y populismo. Buenos Aires: UNDAV, 2013. 41-64.

Berrotarán, Patricia. et al. (eds.). Sueños de bienestar en la nueva Argentina. Estado y política pública durante el peronismo, 1946-1955. Buenos Aires: Imago Mundi, 2004.

Canovan, Margaret. "Trust the People! Populism and the Two Faces of Democracy". Political Studies 42.1 (1999): 2-16.

Groppo, AlejandRo. Los dos príncipes. Un estudio comparado del populismo latinoamericano. Villa María: Editorial Universidad Nacional de Villa María, 2009.

HOBSBAwn, ERic. Sobre la historia. Barcelona: Crítica, 2002.

LaClau, ERnesto. Política e ideología en la teoría marxista del Estado. Capitalismo, fascismo, populismo. Madrid: Siglo XXI, 1977. - La razón populista. Buenos Aires: FCE, 2005. y Chantal Moufre. Hegemonía y estrategia socialista. Madrid: FCE, 1985.

Lichtmajer, JuAn Pablo. "Taming the Desert: Nation and Heterogeneity in Nineteenth-Century Argentina". Conferencia Identification and Politics Workshop II. Universidad de Essex: Gran Bretaña, 2002.

LVOVICH, Daniel y JuAN SuRIANo (eds.). Las políticas sociales en perspectiva histórica: Argentina 1870-1952. Buenos Aires: Prometeo, 2006. Mackinnon, Moira y Mario Petrone (comps.). Populismo y neopopulismo, el problema de la Cenicienta. Buenos Aires: Eudeba, 2010. 
Marchart, Oliver. "In the Name of the People: Populist Reason and the Subject of the Political". Diacritics 35. 3 (2005): 3-19.

MAZZuCA, SEBASTIÁn. "The Rise of Rentier Populism". Journal of Democracy 24 (2013): 108-22.

Olivares, NiColás. "Presidencialismo populista vs presidencialismo deliberativo". Estudios 33 (2015): 31-47.

PanizZA, Francisco. "Fisuras entre populismo y democracia en América Latina". Carlos De La Torre y Enrique Perezzotti (eds.). El retorno del pueblo. Populismo y nuevas democracias. Quito: Flacso, 2008. 77-95. . El populismo como espejo de la democracia. Buenos Aires: FCE, 2009.

Quiroga, VIRGINIA. "Debates y recepciones de la perspectiva laclausiana del populismo. Pueblo e instituciones en los discursos populistas latinoamericanos". POSTData 19. 2 (2015): 377-394.

RANCIÈRE, JACQUES. El desacuerdo. Buenos Aires: Nueva Visión, 1996. . "Who Is the Subject of the Rights of Man?" South Atlantic Quarterly 103 (2004): 297-310.

RETAMOZO, MARTín. "La teoría del populismo de Ernesto Laclau: una introducción”. Estudios Políticos 41 (2017): 157-184.

TAGGarT, Paul. Populism. Buckingham: Open University Press, 2000.

Torre, JuAn Carlos y Elisa PASTORIZA. "La democratización del bienestar". Juan Carlos Torre (comp.). Los años peronistas (1943-1955). Buenos Aires: Sudamericana, 2002. 257-312.

STAVRAKAKIS, YannIS. "Antinomies of Formalism: Laclau's Theory of Populism and the Lessons from Religious Populism in Greece". Journal of Political Ideologies 9. 3 (2004): 253-267. 